\title{
Identification of an AR mutation in Klinefelter syndrome during evaluation for penoscrotal hypospadias
}

\author{
Sezer Acar, ${ }^{1}$ Hale Tuhan, ${ }^{1}$ Elçin Bora, ${ }^{2}$ Korcan Demir, ${ }^{1}$ Hüseyin Onay, ${ }^{3}$ \\ Derya Erçal, ${ }^{4}$ Ece Böber, ${ }^{1}$ Ayhan Abacı ${ }^{1}$
}

\begin{abstract}
${ }^{1}$ Department of Pediatric Endocrinology, Dokuz Eylul University Faculty of Medicine, Izmir, ${ }^{2}$ Department of Medical Genetics, Dokuz Eylul University Faculty of Medicine, Izmir, ${ }^{3}$ Department of Medical Genetics, Ege University Faculty of Medicine, Izmir, ${ }^{4}$ Department of Pediatric Genetics, Dokuz Eylul University Faculty of Medicine, Izmir, Turkey
\end{abstract}

\begin{abstract}
Genital anomalies, ranging from female genitalia to milder degrees of undervirilization, are rarely reported in Klinefelter syndrome, in which a male is classically expected to be born with male external genitalia. Though androgen insensitivity syndrome (AIS) is one of the possible pathogenic mechanisms also in Klinefelter syndrome with genital anomalies, to date the $\boldsymbol{A R}$ gene has not been analyzed in any of the published cases of Klinefelter syndrome of the milder phenotype, except for those patients presenting with a severe phenotype, such as female external genitalia. Lack of interest in considering androgen insensitivity in Klinefelter syndrome with a milder phenotype of genital anomalies may impede its identification through an accurate diagnosis. We present a 14-month-old boy with penoscrotal hypospadias, micropenis, and a ventral penile chordee abnormality who was observed to have both a $47, \mathrm{XXY}$ karyotype and a known missense mutation in the $A R$ gene that was inherited from his mother. Although it is recommended that Klinefelter syndrome be considered in the differential diagnosis of penoscrotal abnormalities, mutations in specific genes involved in androgen synthesis or responsiveness should also be investigated.
\end{abstract}

Key words: Androgen insensitivity syndrome, Androgen receptor, Hypospadias, Klinefelter syndrome

\section{INTRODUCTION}

Klinefelter syndrome (KS) is a common chromosomal abnormality with an incidence of $1 / 600$ to

Address for correspondence:

Ayhan Abac1, Associate Professor, M.D., Department of

Pediatric Endocrinology, Dokuz Eylul University, Faculty of

Medicine, Narlıdere, İzmir, 35340, Turkey;

Tel.: +90 232 4126076, Fax: +90 2324126076 ,

E-mail: ayhanabaci@gmail.com

Received: 04-04-2017, Accepted: 12-06-2017
$1 / 1000$ live births and is often not diagnosed until adolescence or adulthood. ${ }^{1}$ Although different genetic types of KS have been identified, 47, XXY is the most frequent karyotype. ${ }^{2} \mathrm{KS}$ is clinically characterized by oligo-azoospermia, hypergonadotropic hypogonadism, gynecomastia, and infertility in adults. While KS patients are classically born with normal male external genitalia, a number of patients with KS have been reported to have genital malformations. ${ }^{1,2}$ The genital malformations in these patients are thought 
to be related to in utero testosterone insufficiency, androgen insensitivity, CAGn trinucleotide polymorphism, and $D A X 1$ duplication. ${ }^{1}$ Androgen insensitivity syndrome (AIS), the most frequent cause of 46,XY disorders of sex development, is due to mutations in the androgen receptor $(A R)$ gene, which is located on the $\mathrm{X}$ chromosome at Xq12. ${ }^{3}$ AIS is associated with a variety of phenotypes, ranging from female genitalia (complete AIS, CAIS) to milder degrees of undervirilization (partial AIS, PAIS). ${ }^{3,4}$ While a combination of CAIS and 47,XXY has been documented in nine cases, the combination of PAIS and 47,XXY has not been described to date. ${ }^{4-12}$ We present a 14-month old boy with penoscrotal hypospadias, micropenis, and ventral penile chordee who was found to have a 47,XXY karyotype and a known missense mutation in the $A R$ gene.

\section{CASE REPORT}

A 14-month-old male was first referred to our department due to penoscrotal malformation. The patient was born to a healthy 23 -year old mother after successful in vitro fertilization. Prenatal screening tests were normal and his mother had reported no health problems. The parents were nonconsanguineous. The thirty-three year old father had subclinical hypothyroidism and reduced sperm counts in the ejaculate (oligozoospermia). Physical examination of the case revealed a height of $82 \mathrm{~cm}$ (SD score 1.50), weight $16.2 \mathrm{~kg}$ (SD score 3.4), penoscrotal hypospadias, and ventral chordee abnormality with bilateral normal testes $(2 / 2 \mathrm{ml})$. Stretched penile length was $2.6 \mathrm{~cm}(<-2$ SDS). Laboratory studies showed normal biochemistry, follicle stimulating hormone $1.37 \mathrm{mIU} / \mathrm{mL}$ (normal range, $0.3-4.6 \mathrm{mIU} / \mathrm{mL}$ ), luteinizing hormone $<0.2$ $\mathrm{mIU} / \mathrm{mL}$ (normal range, $0.04-0.42 \mathrm{mIU} / \mathrm{mL}$ ), total testosterone $<0.1 \mathrm{ng} / \mathrm{mL}$ (normal range $<0.2 \mathrm{ng} / \mathrm{mL}$ ), 17 -hydroxyprogesterone $<0.3 \mathrm{ng} / \mathrm{ml}$ (normal range $<1.8 \mathrm{ng} / \mathrm{ml}$ ), androstenedione $<0.3 \mathrm{ng} / \mathrm{mL}$ (normal range $<0.9 \mathrm{ng} / \mathrm{ml}$ ). Pelvic ultrasonography revealed no ovarian or uterine tissue. Following three days of human chorionic gonadotropin administration (1000 $\mathrm{U} /$ day) total testosterone increased to $1.32 \mathrm{ng} / \mathrm{mL}$, indicating normal androgen synthesis. Chromosomal analysis revealed a 47,XXY karyotype.

The presence of undervirilization necessitated further genetic analysis and $A R$ sequencing was performed. The coding exons, the 5' UTR and the 3 ' UTR regions, and the exon-intron boundaries of the $A R$ gene were sequenced with the MiSeq NGS system using V2 chemistry (Illumia, San Diego, CA, USA) according to the manufacturer's instructions. We detected a previously reported heterozygous missense mutation in exon 1 of the $A R$ gene (p.P392S, c. $1174 \mathrm{C}>\mathrm{T}) .{ }^{13-15}$ While the father had no mutation in the $A R$ gene, the mother carried the same $A R$ mutation which is consistent with an X-linked pattern of PAIS.

Due to having a heterozygous AR mutation, the mother was evaluated. The twenty-three year old otherwise healthy mother had a normal menstrual cycle (between 28-32 days). She had no hirsutism or acne and the Ferriman-Gallway index score was 6 (normal $<8$ ). Hormonal evaluation revealed normal results: follicle stimulating hormone level $3.6 \mathrm{mIU} /$ $\mathrm{mL}$ (normal, 3.5-8.7); luteinizing hormone $2.9 \mathrm{mIU} /$ $\mathrm{mL}$ (normal, 2.0-9.1); prolactin $7.9 \mathrm{ng} / \mathrm{mL}$ (normal, 3.8-26.7), thyroid stimulating hormone $1.5 \mathrm{mIU} / \mathrm{mL}$, free T4 $1.46 \mathrm{ng} / \mathrm{dL}, 17 \alpha$-hydroxyprogesterone $1.2 \mathrm{ng} /$ $\mathrm{mL}$, dehydroepiandrosterone-sulphate $211.5 \mu \mathrm{g} / \mathrm{dL}$, total testosterone $0.35 \mathrm{ng} / \mathrm{mL}(0.10-0.75)$, and free testosterone concentrations $0.85 \mathrm{pg} / \mathrm{mL}(0.29-3.18)$. Pelvic ultrasonography could not be performed.

\section{DISCUSSION}

In the present study, we describe for the first time, to our knowledge, a combination of KS, manifesting with penoscrotal hypospadias, micropenis, and ventral penile chordee, and a point mutation in the first exon of the $A R$ gene indicative of $A R$-mutation positive PAIS. The diagnosis of KS was confirmed via the identification of the 47,XXY karyotype. Although some cases of KS with CAIS have been documented, a combination of KS and PAIS has not previously been described, nor has the pathophysiological mechanism behind the coexistence of these two latter diseases as yet been investigated. KS patients classically present with normal external male genitalia. However, those with genital abnormalities ranging from mild anomalies (isolated hypospadias, micropenis, cryptorchidism) to moderate undervirilization (penoscrotal abnormalities) have rarely been published in the literature. ${ }^{1,16-18}$ In these reports, though androgen insensitivity has 
been postulated as a possible mechanism, the $A R$ gene was not analyzed in any of them. However, in three patients with both 47,XXY and genital abnormalities, Lee et $\mathrm{al}^{1}$ demonstrated normal androgen-binding characteristics in genital skin fibroblasts. It is thus evident, as also demonstrated in our case, that the $A R$ gene should be analyzed in KS patients with genital abnormalities.

The few published cases with the combination of $\mathrm{KS}$ and AIS had female external genitalia, which is compatible with CAIS, and most of them had high FSH, LH and total testosterone levels..$^{4-12}$ Uehera et al reported a case with 47,XXY and CAIS that had both homozygous nonsense mutations in exon 4 (c.2280C $>$ T, p.Q640X) and in exon 5 (c.2615G>A, p.W751X) of the $A R$ gene. ${ }^{12}$ Girardin et al identified a homozygous known missense mutation in exon 5 of the $A R$ gene (c. 2560A $>$ T, p.Q733L) in a patient with a $47, \mathrm{XXY}$ karyotype and CAIS. ${ }^{4}$ In our KS patient with features including penoscrotal hypospadias, micropenis, and ventral penile chordee abnormalities, we have described a known missense mutation in exon 1 in the $A R$ gene (p.P392S). To date, the p.P392S mutation has been identified in 8 cases ( 4 penile hypospadias, 1 penoscrotal hypospadias, 1 isolated micropenis, and 2 isolated infertility), which indicated that this mutation, in line with the current case, mostly leads to a mild phenotype in patients with AIS. ${ }^{13-15}$ The mutation in exon 1 of the $A R$ gene is located within an important region for transcriptional activity of the receptor. However, in contrast to the above data, Hiort et $\mathrm{a}^{19}$ showed that the p.P392S mutation did not lead to gross alterations in the transcriptional activity of the androgen receptor. This mutation may have different in vivo and in vitro activity and it is generally thought that the p.P392S mutation normally leads to a mild phenotype in male external genitalia.

The X-linked $A R$ gene mutation is the most common cause of 46,XY disorders of sex development (DSD). Usually, hemizygous mutations in the $A R$ gene lead to AIS in individuals with a 46,XY karyotype. However, in males with two $\mathrm{X}$ alleles, as is the case in individuals with a 47,XXY karyotype, the occurrence of $A R$ gene inactivation could be explained differently. Partial AIS can occur in XXY when a non-mutant $\mathrm{X}$ is inactivated or a mutant allele is preferentially expressed. ${ }^{10}$ CAIS in Klinefelter syndrome can also occur with uniparental disomy (UPD), as described by Jacobs et al. ${ }^{20}$ Therefore, it is likely that the mutant $\mathrm{X}$ allele expression could be responsible for the moderate PAIS presentation in our patient with the heterozygous $A R$ gene mutation.

While $A R$ gene mutations lead to various degrees of genital abnormalities in males, CAG repeat length variation (polyglutamine) that encodes on the $1^{\text {st }}$ exon of the $A R$ gene and heterozygous $A R$ mutations have been shown to be associated with hyperandrogenism or development of polycystic ovary syndrome in adult women. ${ }^{21,22}$ Hyoun et a ${ }^{22}$ reported a 37-year old woman who gave birth to a child with CAIS diagnosed with polycystic ovary syndrome (PCOS), probably due to a heterozygous $A R$ mutation. In contrast, the mother of our patient had a heterozygous $A R$ mutation not previously described in polycystic ovary syndrome. Since there are limited data demonstrating the relationship between heterozygous $A R$ mutations and PCOS in adult females, there is a need for further studies to clarify this association.

Due to long-term testosterone deficiency, comorbid conditions such as bone and muscle mass loss, obesity, deterioration of glucose metabolism, and type 2 diabetes may occur in the progressive stages of puberty in cases with KS..$^{23,24}$ In addition, patients with PAIS who were assigned male have relative testosterone deficiency as well. ${ }^{25}$ Thus, in both diseases, testosterone replacement is recommended to induce puberty, to enhance virilization post puberty and to prevent such comorbidities associated with hypogonadism. However, the treatment approach is not clear in patients who have both PAIS and KS and who are raised male. We consider that testosterone replacement could be appropriate during the follow-up period of puberty in our case with both KS and PAIS. The long-term outcome will help us to improve our approach to the treatment of these patients.

In conclusion, this is, to our knowledge, the first description of a male case with the combination of the 47,XXY and PAIS phenotype. As far as we know, the patients previously reported with both $47, \mathrm{XXY}$ and AIS all had a CAIS phenotype. Random X inactivation of the healthy allele probably caused the PAIS phenotype in our KS patient. $A R$ gene muta- 
tions, which are the most common cause of $46, \mathrm{XY}$ disorders of sex development, must be excluded in undervirilized males with KS.

\section{ACKNOWLEDGEMENTS}

This research did not receieve any specific grant from any funding agency in the public, commercial or not-for-profit sector.

\section{STATEMENT OF ETHICS}

Written informed consent of the parents was obtained for this case report.

\section{DISCLOSURE STATEMENT}

The authors have nothing to disclose.

\section{REFERENCES}

1. Lee YS, Cheng AW, Ahmed SF, Shaw NJ, Hughes IA, 2007 Genital anomalies in Klinefelter's syndrome. Horm Res 68: 150-155.

2. Pacenza N, Pasqualini T, Gottlieb S, et al, 2012 Clinical Presentation of Klinefelter's Syndrome: Differences According to Age. Int J Endocrinol 2012: 324835.

3. Quigley CA, Tan JA, He B, et al, 2004 Partial androgen insensitivity with phenotypic variation caused by androgen receptor mutations that disrupt activation function 2 and the NH(2)- and carboxyl-terminal interaction. Mech Ageing Dev 125: 683-695.

4. Girardin CM, Deal C, Lemyre E, et al, 2009 Molecular studies of a patient with complete androgen insensitivity and a 47,XXY karyotype. J Pediatr 155: 439-443.

5. Case records of the Massachusetts General Hospital. Weekly clinicopathological exercises. Case 13-1990. A 23-year-old woman with primary amenorrhea, an abnormal karyotype, and bilateral inguinal masses. $\mathrm{N}$ Engl J Med 322: 917-925.

6. Bartsch-Sandhoff M, Stephan L, Rohrborn G, Pawlowitzki IH, Scholz W, 1976 A case of testicular feminization with the karyotype 47, XXY. Hum Genet 31: 59-65.

7. Gerli M, Migliorini G, Bocchini V, et al, 1979 A case of complete testicular feminisation and 47, XXY karyotype. J Med Genet 16: 480-483.

8. German J, Vesell M, 1966 Testicular feminization in monozygotic twins with 47 chromosomes (XXY). Ann Genet 9: 5-8.

9. Milcou SM, Serban AI, Ionesco B, et al, 1972 Testicular feminization with ambosexualization at puberty and 46
XY-47 XXY mosaicism. Ann Endocrinol (Paris) 33: 607-621.

10. Muller U, Schneider NR, Marks JF, Kupke KG, Wilson GN, 1990 Maternal meiosis II nondisjunction in a case of 47,XXY testicular feminization. Hum Genet 84: 289-292.

11. Saavedra-Castillo E, Cortes-Gutierrez EI, Davila-Rodriguez MI, Reyes-Martinez ME, Oliveros-Rodriguez A, 2005 47,XXY female with testicular feminization and positive SRY: a case report. J Reprod Med 50: 138-140.

12. Uehara S, Tamura M, Nata M, et al, 1999 Complete androgen insensitivity in a 47,XXY patient with uniparental disomy for the X chromosome. Am J Med Genet 86: 107-111.

13. Audi L, Fernandez-Cancio M, Carrascosa A, Andaluz P, et al, 2010 Novel (60\%) and recurrent (40\%) androgen receptor gene mutations in a series of 59 patients with a 46,XY disorder of sex development. J Clin Endocrinol Metab 95: 1876-1888.

14. Bhangoo A, Paris F, Philibert P, Audran F, Ten S, Sultan C, 2010 Isolated micropenis reveals partial androgen insensitivity syndrome confirmed by molecular analysis. Asian J Androl 12: 561-566.

15. Kalfa N, Philibert P, Werner R, et al, 2013 Minor hypospadias: the "tip of the iceberg" of the partial androgen insensitivity syndrome. PLoS One 8: e61824.

16. Das C, Sahana PK, Sengupta N, Roy M, Dasgupta R, 2013 Unusual presentation of Klinefelter syndrome. Indian J Endocrinol Metab 17: 683-684.

17. Hodhod A, Umurangwa F, El-Sherbiny M, 2015 Prepubertal diagnosis of Klinefelter syndrome due to penoscrotal malformations: Case report and review of literature. Can Urol Assoc J 9: 333-336.

18. Sasagawa I, Nakada T, Hashimoto T, et al, 1992 Klinefelter's syndrome associated with unilateral cryptorchidism and chordee without hypospadia. Urol Int 48: 428-429.

19. Hiort O, Holterhus PM, Horter T, et al, 2000 Significance of mutations in the androgen receptor gene in males with idiopathic infertility. J Clin Endocrinol Metab 85: 2810-2815.

20. Jacobs PA, Hassold TJ, Whittington E, et al, 1988 Klinefelter's syndrome: an analysis of the origin of the additional sex chromosome using molecular probes. Ann Hum Genet 52: 93-109.

21. Lin LH, Baracat MC, Maciel GA, Soares JM Jr, Baracat EC, 2013 Androgen receptor gene polymorphism and polycystic ovary syndrome. Int J Gynaecol Obstet 120: 115-118.

22. Nam H, Kim CH, Cha MY, Kim JM, Kang BM, Yoo HW, 2015 Polycystic ovary syndrome woman with heterozygous androgen receptor gene mutation who gave birth to a child with androgen insensitivity syndrome. Obstet Gynecol Sci 58: 179-182. 
23. Bhasin S, Cunningham GR, Hayes FJ, et al, Task Force, Endocrine Society, 2010 Testosterone therapy in men with androgen deficiency syndromes: an Endocrine Society clinical practice guideline. J Clin Endocrinol Metab 95: 2536-2559.

24. Chang S, Skakkebæk A, Gravholt CH, 2015 Klinefelter Syndrome and medical treatment: hypogonadism and beyond. Hormones (Athens) 14: 531-548.

25. Weidermann W, Peters B, Romalo G, Spindler K-D, Schweikert H-U, 1998 Response to androgen treatment in a patient with partial androgen insensitivity and a mutation in the deoxyribonucleic acid-binding domain of the androgen receptor. J Clin Endocrinol Metab 83: 1173-1176. 